\title{
BMJ open Are physiological attributes of jockeys
predictors of falls? A pilot study
}

\author{
P Hitchens, ${ }^{1}$ L Blizzard, ${ }^{1}$ G Jones, ${ }^{1}$ L Day, ${ }^{2}$ J Fell ${ }^{3}$
}

To cite: Hitchens $P$ Blizzard L, Jones G, et al. Are physiological attributes of jockeys predictors of falls? A pilot study. BMJ Open 2011;1:e000142. doi:10.1136/bmjopen-2011000142

- Prepublication history for this paper is available online. A supplementary appendix, containing detailed physiological measurements of jockeys and track-work riders, is available online. To view these files please visit the journal online (http:// bmjopen.bmj.com).

Received 13 April 2011 Accepted 16 May 2011

This final article is available for use under the terms of the Creative Commons Attribution Non-Commercial 2.0 Licence; see http://bmjopen.bmj.com

\footnotetext{
${ }^{1}$ Menzies Research Institute, University of Tasmania, Hobart, Tasmania, Australia ${ }^{2}$ Monash Injury Research Institute, Monash University, Victoria, Australia

${ }^{3}$ School of Human Life Sciences, University of Tasmania, Launceston, Tasmania, Australia
}

Correspondence to Peta Hitchens:

Peta.Hitchens@utas.edu.au

\section{ABSTRACT}

Objectives: This pilot study describes the physiological attributes of jockeys and track-work riders in Tasmania and investigates whether these attributes are associated with falls.

Methods: All jockeys and track-work riders licensed in Tasmania were invited to participate. The study group consisted of eight jockeys (two female, six male) and 20 track-work riders (14 female, six male). Measures of anthropometry, balance, reaction time, isometric strength, vertical jump, glycolytic and aerobic fitness, flexibility and body composition were conducted. Tests were designed to assess specific aspects of rider fitness and performance relevant to horse racing. For a subset of participants $(n=14)$, the authors obtained information on falls and injuries. The authors used Poisson regression to estimate incidence rate ratios.

Results: Jockeys had better balance, a faster mean reaction time, a lower fatigue index and a higher estimated $\mathrm{V}_{2 \max }$ than their track-work riding counterparts. Jockeys were also younger and smaller in stature than track-work riders, and when differences in body mass were taken into account, they had a greater muscular strength and muscular (alactic) power. Important factors found to be associated with falls were lower aerobic and anaerobic fitness, greater muscular strength and power, and riding with the full foot in the stirrup irons compared with riding on the ball of the foot.

Conclusion: This pilot study shows that physiological attributes of jockeys and track-work riders can predict their risk of falling and are measurable using methods feasible for large-scale fieldwork.

\section{INTRODUCTION}

The profession of a jockey or track-work rider in the thoroughbred racing industry is physically demanding. Riding race horses, during track-work or during a race, places demands on all three energy pathways (alactic, lactic and aerobic). Strength, strength endurance, balance, reaction time and flexibility are all considered to be important attributes of a successful rider. ${ }^{12}$

A professional jockey in Australia may have as many as 1000 race rides per year, and may ride in races that range in distance from $800 \mathrm{~m}$ to $3600 \mathrm{~m}$ in races without jumps ('on

\section{ARTICLE SUMMARY}

Article focus

- Riding racehorses is a physically demanding and hazardous occupation, with most injuries to jockeys caused by falls.

- This study aims to investigate the association between physiological attributes and risk of falls for jockeys and track-work riders.

Key messages

- Lower anaerobic and aerobic fitness, and higher muscular strength and power were associated with greater risk of falls.

n Placement of the foot in the stirrup irons was also found to be associated with falls.

- This pilot study has confirmed that it is feasible to measure the physiological attributes of jockeys and track-work riders that are predictive of the risk of falling.

Strengths and limitations of this study

n This was the first study to investigate whether physiological attributes are associated with falls to jockeys and track-work rides.

- Tests were deliberately restricted to those that could be conducted with robustly constructed and transportable equipment.

- We were able to recruit only a small number of participants, but our sample comprised $44 \%$ of the jockey population and $24 \%$ of the track-work rider population licensed in Tasmania.

- Some refinements to the testing methodology are needed.

the flat') or from $2800 \mathrm{~m}$ to $5500 \mathrm{~m}$ in races over jumps. Jockeys may also undertake trackwork riding. Track-work may involve riding many horses in training and at varying intensities from walking a horse, slow or fast work, jump outs (practice jumping out of the barriers and galloping over a short distance) or barrier trials (unofficial races generally over shorter distances and with fewer starters, in which a horse or jockey may be assessed for suitability to compete in official races). Track-work riders are not able to ride in professional races unless they are a licensed jockey, and are generally heavier in weight than jockeys who need to be able to ride at 
weights as low as $51 \mathrm{~kg}$ (flat races) or $64 \mathrm{~kg}$ (jumps races).

There have been several studies describing the physical attributes and dietary habits of jockeys, ${ }^{1}{ }^{3-7}$ and the demands of riding in races. ${ }^{18}$ The physiological attributes of grooms and exercise riders, ${ }^{9}$ and the physiological demands of riding for equestrian and recreational horse riders ${ }^{2}{ }^{10-14}$ have also been described. There is limited information on the fitness of jockeys, however, and no study has reported the fitness characteristics of track-work riders despite their integral role within the racing industry. The feasibility of undertaking measurements of the physiological attributes of this highly mobile occupational group, using techniques suitable for large-scale fieldwork, has not been demonstrated.

Further, there has been no investigation of the association between physiological attributes and risk of falls for jockeys and track-work riders. Riding racehorses is a hazardous occupation, and most injuries to jockeys are caused by falls. ${ }^{15}$ We have investigated risk factors for raceday jockey falls in flat racing using race-day data, and found that jockey-related factors included female sex of jockey, being an apprentice jockey, holding an amateur licence, and having fewer previous rides at a meeting. ${ }^{16}$ We hypothesise that some physiological attributes of jockeys may also contribute to the risk of falling. Given the lack of information on this occupational group, we undertook a study to describe the physiological attributes of jockeys and track-work riders licensed to ride in Tasmania and conducted a preliminary investigation into whether these attributes are associated with falls.

\section{METHODS}

Every jockey ( $\mathrm{n}=18$; six apprentice, 12 fully licensed) and track-work rider $(\mathrm{n}=85)$ licensed to ride in Tasmania, the island state of Australia, was invited to participate. Reasons for non-participation included riders not currently or regularly riding, injury or illness, living interstate or being ineligible by reason of age (we excluded riders older than 50 years). The final study group consisted of all of those who made themselves available: eight jockeys (two female fully licensed, four male apprentice, one male fully licensed and one male fully licensed jumps jockey) and 20 track-work riders (14 female, six male). This represents $44 \%$ of the jockey population and $24 \%$ of the track-work rider population in Tasmania.

Each participant was tested at one of three different locations in Tasmania: Menzies Research Institute (Hobart), University of Tasmania Exercise Research Laboratory (Launceston) and the Devonport Racing Club (Devonport). The same equipment was transported to and used at each location. All tests were supervised by the same technician.

Tests were selected on their practicality and portability, and based on previous studies of horse riders ${ }^{1} 28$ 10-14 and performance attributes of athletes. ${ }^{17}$ These tests were designed to assess specific aspects of fitness that may be relevant to the requirements of thoroughbred racing and track-work riding.

Participants were provided with an outline of the test protocols prior to formal testing. Participants were required to be in good health and fully recovered from previous injuries. For jockeys, testing did not occur on the day before or after race day, or at times of significant body mass wasting.

Height was measured to the nearest $0.1 \mathrm{~cm}$ using a Leicester Height Measure (Invicta, Leicester, UK). Body mass was measured to the nearest $0.1 \mathrm{~kg}$ using a Heine Portable Professional Scale (Heine, Dover, New Hampshire). Body mass index (BMI) was calculated. Body composition (total percentage body fat) and bone mineral density $\left(\mathrm{g} / \mathrm{cm}^{2}\right)$ were measured by the technique of dual-energy $\mathrm{x}$-ray absorptiometry using one Lunar DPX densitometer (Lunar, Madison, Wisconsin). Only 11 of the participants underwent a dual-energy x-ray absorptiometry scan, and so these results were not included in the falls analysis.

To measure dynamic unipedal balance, the participant was required to balance in a 'standing-stork' pose (shoes removed, one leg lifted, placing the toes of that foot against the knee of the opposite leg) on a $65 \mathrm{~mm}$ foam insert (Airex Balance-Pad Plus, Alcan Airex AG, Switzerland) for as long as possible. A stopwatch was used to record the time that the participant held the position. The test was repeated three times on each leg. The best result for each leg was used in analysis.

The sit-and-reach test was used to measure flexibility of the lower back, hips and hamstring muscles, and the back and hip joints. Participants placed their feet flat against a $30 \mathrm{~cm}$ high box with shoes and socks removed, and attempted to reach forward as far as possible with knees fully extended. The level of the feet was recorded as the baseline, with positive scores (in $\mathrm{cm}$ ) achieved beyond this point. Participants were permitted three trials, and the best result was recorded. ${ }^{18} 19$

The reaction time was assessed in milliseconds using a hand-held electronic timer with a light as the stimulus, and with depression of a switch by the finger as the response (Balance Systems, Sydney, New South Wales, Australia). Ten practice trials were undertaken, followed by 10 experimental trials. ${ }^{20}$

Strength was measured using isometric dynamometers. Grip strength was measured using a hand-grip dynamometer (Smedley's TTM $100 \mathrm{~kg}$, Tokyo), and shoulder and arm strength using a shoulder/arm dynamometer (TTM $100 \mathrm{~kg}$ ). This involved both push strength (maximal voluntary isometric contraction of the shoulder flexors/adductors) and pull strength (maximum voluntary isometric contraction of the shoulder extensors/abductors). Results were recorded to the nearest $0.5 \mathrm{~kg}$. Leg and back strength was measured using a leg/back dynamometer (Gloria TTM $300 \mathrm{~kg}$, Tokyo). Participants performed a maximum voluntary isometric contraction of the knee and hip extensors, with the knees flexed at $115^{\circ}$ while 
maintaining a vertical spine position. The result was recorded to the nearest $1 \mathrm{~kg}$. Three trials were conducted for all strength tests with the best result used for analysis.

To measure explosive leg power, the standing vertical jump (counter movement jump) was conducted using a Yardstick (Swift Performance Equipment, Lismore, New South Wales, Australia). The best trial was recorded and reported in centimetres jumped. ${ }^{19}$ From this result, peak and mean alactic power were calculated using the Harman formulas. ${ }^{21}$

Anaerobic (lactic) fitness was assessed by the $30 \mathrm{~s}$ cycle test using an air-braked ergometer (Exertech, EX-10, Repco, Huntingdale, Australia). ${ }^{22}$ Mean and peak lactic power were recorded in watts (W) and watts per kilogram of body mass $(\mathrm{W} / \mathrm{kg})$. The fatigue index (percentage decline in power compared with the peak power output) was calculated.

Aerobic fitness was assessed using the YMCA submaximal exercise test performed on a friction-braked cycle ergometer (Monark Ergomedic 828E, Varberg, Sweden) to estimate maximal oxygen uptake $\left(\dot{\mathrm{V}} \mathrm{O}_{2 \max }, \mathrm{ml} / \mathrm{kg}\right.$ / $\min ) .{ }^{17}$

The participants were asked how they positioned their feet in the stirrup irons when riding (riding style). They were classified as riding with their full foot lodged firmly in the irons (full foot), or with the ball of their foot in the irons (ball of foot) or with only the toe of their boot in the iron (toe-in-iron).

Incident data on falls of licensed Tasmanian trackwork riders during track-work were collected by participants completing a diary for 12 months following their fitness assessment. The follow-up period was 1 March 2008 to 31 May 2009. The participants were instructed to record, on a monthly basis, the average number of trackwork rides per week. For each fall, participants were asked to complete an incident report form. Of the trackwork riders, seven returned their diaries.

None of the jockeys returned their track-work diaries. However, we did obtain incident data on falls at race meetings by the seven licensed flat racing jockeys. The one jumps jockey did not have any race rides recorded during the study period. The data were collated through a search of stewards' reports provided by Racing Services Tasmania, the principal racing authority of that state. Racing Information Services Australia (RISA) provided comprehensive data on every race meeting run by Racing Services Tasmania. These data were merged with the incident falls data. Details are provided elsewhere. ${ }^{15}$ To match the number of rides taken by track-work riders, we included race rides during the period 1 June 2007 to 31 May 2009.

Anthropometric (height, mass, BMI, percentage body fat and bone mineral density) and fitness (aerobic, anaerobic, muscular strength and power, flexibility, balance and reaction time) measures of jockeys and trackwork riders were compared using regression analysis. Right-skewed data were log-transformed prior to analysis.
Univariable Poisson regression was used to estimate incidence rate ratios (IRR) with $95 \%$ CIs by modelling the logarithm of the mean number of falls as a function of covariates, with the logarithm of the number of rides as an offset. Interaction of licence type was assessed from the coefficients of product terms. Effect modification was considered present if the test of the coefficient of a product term yielded a $\mathrm{p}$ value less than 0.05 in a dataset expanded with nine duplicates. Results for variables that showed a significant interaction with licence type are reported separately from those where no interaction was present.

To make an assessment of the possible significance of anaerobic fitness factors in a fully powered main study, we expanded the dataset from $n=14$ to $n=28$ (to assess the effects of peak power per kilogram of body mass and fatigue index) and to $n=42$ (to assess the effect of mean power per kilogram of body mass) by duplicating observations.

\section{RESULTS}

Participant age and anthropometric characteristics are described in table 1. Jockeys were younger in age, shorter in height and lower in mass and BMI, and had a lower percentage total body fat and total bone mineral density than track-work riders.

The participant groups were similar in measures of grip strength, shoulder pull strength, and leg and back

Table 1 Descriptive characteristics of jockeys and trackwork riders in Tasmania

\begin{tabular}{|c|c|c|}
\hline Study factor & $\begin{array}{l}\text { Jockeys } \\
(n=8)\end{array}$ & $\begin{array}{l}\text { Track-work } \\
\text { riders }(n=20)\end{array}$ \\
\hline \multicolumn{3}{|l|}{ Age (years) } \\
\hline Median & 27.00 & 36.50 \\
\hline Mean $( \pm S D)$ & $28.75(10.10)$ & $33.20(11.08)$ \\
\hline Range & $18-41$ & $15-47$ \\
\hline \multicolumn{3}{|l|}{ Height $(\mathrm{cm})$} \\
\hline Median & 163.45 & 168.25 \\
\hline Mean $( \pm S D)$ & $163.39(7.08)$ & $166.51(7.36)$ \\
\hline Range & $154.4-174.9$ & $156.6-179.5$ \\
\hline \multicolumn{3}{|l|}{ Mass (kg) } \\
\hline Median & 51.75 & 65.90 \\
\hline Mean $( \pm S D)$ & $55.08(5.87)$ & $67.32(12.51)$ \\
\hline Range & $50.5-66.3$ & $44.2-90.5$ \\
\hline \multicolumn{3}{|c|}{ Body mass index } \\
\hline Median & 20.63 & 24.00 \\
\hline Mean $( \pm S D)$ & $20.62(1.58)$ & $24.13(3.28)$ \\
\hline Range & $18.45-23.27$ & $18.02-30.52$ \\
\hline \multicolumn{3}{|l|}{ Body fat $(\%)^{*}$} \\
\hline Median & 15.90 & 29.45 \\
\hline Mean $( \pm S D)$ & $13.98(3.52)$ & $28.15(8.21)$ \\
\hline Range & $8.50-16.90$ & $17.00-37.60$ \\
\hline \multicolumn{3}{|c|}{ Bone mineral density $\left(\mathrm{g} / \mathrm{cm}^{2}\right)^{*}$} \\
\hline Median & 1.167 & 1.273 \\
\hline Mean $( \pm S D)$ & $1.157(0.068)$ & $1.312(0.103)$ \\
\hline Range & $1.085-1.246$ & $1.206-1.473$ \\
\hline
\end{tabular}


Table 2 Unadjusted and adjusted incidence rate ratios (IRRs) of factors associated with race-day falls by flat racing jockeys $(n=7)$ from 1 June 2007 to 31 May 2009, and with falls during track-work for track-work riders $(n=7)$ from 1 March 2008 to 31 May 2009

\begin{tabular}{|c|c|c|c|c|}
\hline Study factor & Falls & Rides & $\begin{array}{l}\text { Unadjusted } \\
\text { IRR (95\% CI) } \\
\end{array}$ & $\begin{array}{l}\text { Adjusted } \\
\text { IRR }(95 \% \text { Cl)† }\end{array}$ \\
\hline \multicolumn{5}{|l|}{ Licence } \\
\hline Jockey & 13 & 2978 & 1.00 & 1.00 \\
\hline Track-work rider & 24 & 2996 & $1.84(0.90$ to 3.74$)$ & $3.54(2.07 \text { to } 6.06)^{\star \star *}$ \\
\hline \multicolumn{5}{|l|}{ Sex } \\
\hline Male & 15 & 2519 & 1.00 & 1.00 \\
\hline Female & 22 & 3455 & 1.07 (0.52 to 2.19$)$ & $0.45(0.17$ to 1.20$)$ \\
\hline Age & 37 & 5974 & 1.03 (1.00 to 1.06$)$ & $1.05(1.01 \text { to } 1.10)^{*}$ \\
\hline Body mass index & 37 & 5974 & $1.12(1.02 \text { to } 1.21)^{*}$ & $1.15(1.08 \text { to } 1.23)^{\star \star *}$ \\
\hline Log of balance pooled (s) & 37 & 5974 & 0.87 (0.59 to 1.28$)$ & 1.28 (0.95 to 1.72$)$ \\
\hline Flexibility $(\mathrm{cm})$ & 37 & 5974 & 0.99 (0.94 to 1.04$)$ & $0.96(0.91$ to 1.01$)$ \\
\hline \multicolumn{5}{|l|}{ Muscular strength and power } \\
\hline Push strength $(\mathrm{kg})$ & 37 & 5974 & $1.00(0.97$ to 1.03$)$ & $1.00(0.96$ to 1.04$)$ \\
\hline Pull strength $(\mathrm{kg})$ & 37 & 5974 & 1.03 (0.98 to 1.09$)$ & $1.09(1.04 \text { to } 1.14)^{\star \star \star}$ \\
\hline Leg/back strength $(\mathrm{kg} / 10)$ & 37 & 5974 & $1.11(1.00 \text { to } 1.23)^{*}$ & 1.05 (0.98 to 1.13$)$ \\
\hline Pooled grip strength (kg) & 37 & 5974 & 1.05 (0.96 to 1.13$)$ & 1.02 (0.96 to 1.09$)$ \\
\hline Absolute jump height $(\mathrm{cm})$ & 37 & 5974 & 0.97 (0.92 to 1.02$)$ & $0.93(0.85$ to 1.01$)$ \\
\hline Mean power (W/kg) & 37 & 5974 & $1.19(0.94$ to 1.50$)$ & $1.14(0.91$ to 1.42$)$ \\
\hline \multicolumn{5}{|l|}{ Anaerobic fitness } \\
\hline Mean power (W/kg) & 37 & 5974 & $0.90(0.77$ to 1.05$)$ & 0.85 (0.67 to 1.09$)$ \\
\hline Peak power (W/kg) & 37 & 5974 & $0.91(0.82$ to 1.00$)$ & $0.87(0.74$ to 1.02$)$ \\
\hline Total work (hectojoules/kg) & 37 & 5974 & 0.78 (0.46 to 1.32$)$ & $0.83(0.34$ to 1.98$)$ \\
\hline Fatigue index (\%) & 37 & 5974 & $0.97(0.96 \text { to } 0.99)^{\star \star *}$ & $0.98(0.96$ to 1.00$)$ \\
\hline \multicolumn{5}{|l|}{ Aerobic fitness } \\
\hline $\mathrm{VO}^{2} \max (\mathrm{ml} / \mathrm{kg} / \mathrm{min})$ & 37 & 5974 & $0.97(0.93$ to 1.01$)$ & $0.93(0.90 \text { to } 0.97)^{\star \star *}$ \\
\hline \multicolumn{5}{|l|}{ Riding style } \\
\hline Ball of foot $(n=9)$ & 19 & 4176 & 1.00 & 1.00 \\
\hline Toe-in-iron $(n=2)$ & 5 & 684 & $1.61(0.99$ to 2.61$)$ & $1.12(0.60$ to 2.08$)$ \\
\hline Full foot $(n=3)$ & 13 & 1114 & $2.56(1.31 \text { to } 5.04)^{\star *}$ & $2.37(1.46 \text { to } 3.85)^{\star \star \star}$ \\
\hline
\end{tabular}

strength. Jockeys had a better balance, a faster reaction time, a lower fatigue index and a higher estimated $\dot{\mathrm{V}} \mathrm{O}_{2 \max }$, but were less flexible and had lower shoulder push strength than track-work riders. Additionally, jockeys had greater muscular strength and power, once accounting for the body mass (per kilogram) of the participant. Detailed results in relation to the physiological attributes of jockeys and track-work riders are available in a supplementary appendix.

Table 2 presents unadjusted and adjusted (for age and sex) incidence rate ratios of physiological attributes associated with falls for factors that did not differ between jockeys and track-work riders. Seven track-work riders returned their fall and injury diaries. The trackwork riders reported a total of 24 falls from 2996 rides (0.80 falls per 100 rides). Of these falls, 13 (54\%) resulted in an injury being sustained. A total of 13 falls from 2978 race rides ( 0.44 falls per 100 rides) were experienced by the jockeys in our study. Of these falls, three $(23 \%)$ resulted in an injury being sustained.

Table 2 shows that a lower aerobic fitness was associated with a greater risk of falls. Greater shoulder pull strength was also associated with a higher incidence of falls (table 2). The effect of some measures of body composition and muscular power differed by licence type. Table 3 shows that jockeys with a higher peak alactic power had a higher fall incidence than other jockeys, with the opposite being the case for track-work riders.

Placement of the foot in the stirrup irons was associated with falls. Both jockeys and track-work riders that ride with the full foot in the stirrup irons had a higher fall incidence than did those riding with the ball of the foot in the irons (table 2).

\section{DISCUSSION}

In this investigation of the physiological attributes of jockeys and track-work riders in Tasmania, we found that jockeys had better balance, faster mean reaction time, lower fatigue index and higher estimated $\dot{\mathrm{V}} \mathrm{O}_{2 \max }$. They were younger and smaller in stature than track-work riders, and when differences in body mass were taken into account, they had greater muscular strength and alactic power (derived from the vertical jump). 
Table 3 Adjusted incidence rate ratios (IRRs) of factors associated with falls that differed by jockey and track-work riders

\begin{tabular}{|c|c|c|}
\hline Study factor & $\begin{array}{l}\text { Jockey } \\
\text { IRR }(95 \% \text { CI)† }\end{array}$ & $\begin{array}{l}\text { Track-work rider } \\
\text { IRR }(95 \% \mathrm{CI}) \dagger\end{array}$ \\
\hline Body mass (kg) & $0.82(0.81 \text { to } 0.83)^{\star \star *}$ & $1.05(1.02 \text { to } 1.07)^{\star \star *}$ \\
\hline Height $(\mathrm{cm})$ & $0.92(0.89 \text { to } 0.96)^{\star \star \star}$ & 1.05 (0.92 to 1.19$)$ \\
\hline \multicolumn{3}{|l|}{ Muscular power } \\
\hline Peak power $(\mathrm{W} / \mathrm{kg})$ & $1.08(1.04 \text { to } 1.13)^{\star \star \star}$ & $0.95(0.94 \text { to } 0.96)^{\star \star \star}$ \\
\hline
\end{tabular}

Furthermore, in a study of falls experienced by jockeys on race-days and by track-work riders during track-work, we found older age, higher BMI, greater shoulder pull strength, lower aerobic fitness, and riding with the full foot in the stirrup irons were factors associated with an increased incidence of falls. Additionally, jockeys who were lower in mass or shorter in height, or had greater peak alactic power (per kilogram of body mass) had a higher fall incidence than other jockeys, with the reverse being the case for track-work riders.

The anthropometric attributes of jockeys reported in this study were generally similar to those of New Zealand and Irish jockeys reported in previous studies, ${ }^{5-7}$ but the track-work riders more closely resembled the anthropometric characteristics of participants in equestrian studies. ${ }^{11} 14$ The grip strength of the jockeys and trackwork riders was similar to that of participants in a study of Irish jockeys, ${ }^{6}$ but higher than that of participants in an equestrian study. ${ }^{14}$ Both groups also had aboveaverage relative $\dot{\mathrm{V}} \mathrm{O}_{2 \max }$ and average flexibility compared with normative data, ${ }^{17}$ and greater anaerobic (lactic) power than those from an equestrian study. ${ }^{14}$ We do not have any normative data on balance or reaction times for this age group with which to make comparisons.

In this study, lower anaerobic and aerobic fitness were associated with a greater risk of falls. Only the association with aerobic fitness was statistically significant, but if our participants are representative of jockeys and track-work riders in general, the association with measures of anaerobic fitness would have been statistically significant for peak and mean power per kilogram of body mass and for fatigue index had the sample size been just one or two times greater (data not shown). This is the first report of a finding that fitness is associated with falls by jockeys and track-work riders, but it is consistent with findings for injuries to other occupational groups including manual material handlers ${ }^{23}$ and military personnel. $^{2425}$

There was some evidence that higher muscular strength and power were positively associated with falls. This was seen for shoulder pull strength and for peak alactic power in jockeys. This may be due to riders with greater strength and power being placed on difficult or fractious horses because it is industry practice, where possible, to assign this task to the most capable riders. Possibly consistent with this finding, industrial workers with greater isometric strength have been reported to be at greater risk of back problems. ${ }^{26}$ On the other hand, opposite results were found for peak alactic power of track-work riders in our study. This may reflect a true difference between jockeys and track-work riders, but we cannot discount the possibility that the associations with muscular strength and power are chance findings owing to the small sample size.

Placement of the foot in the stirrup irons was found to be associated with falls for both jockeys and track-work riders. Those riding with the full foot in the stirrup irons had a higher fall incidence than those riding with the ball of the foot in the irons. We also found a small and statistically insignificant increase in risk for those who ride with their toe in the iron. Owing to safety concerns, all principal racing authorities in Australia require apprentices to ride with at least their ball of their foot in the irons until they have gained adequate experience (Ring, personal communication, 2010). We had too few inexperienced riders in our study to investigate this issue.

This study adds to the limited information available on the physiological attributes of jockeys, and is the first study to report comprehensively on the physiological characteristics of track-work riders. A strength of this study was the comprehensive range of tests implemented. For the benefit of industry participants and researchers, these results have been made available in a supplementary appendix. Additionally, this allowed us to assess the feasibility of applying this battery of tests in large-scale fieldwork with this highly mobile occupational group, and we were able to get some confirmation that doing so was practicable. In a novel contribution, this was the first study to investigate whether these attributes are associated with falls to riders in both licence groups, and we found that measurements of fitness and riding style were predictors of falls. So too were the measurements of muscular strength and power, albeit in an unexpected direction.

However, some limitations of this study should be borne in mind. Because our intention was to investigate methods appropriate for large-scale fieldwork, we deliberately restricted tests to those that could be conducted with robustly constructed and transportable equipment. We did not use more sensitive equipment that may be more accurate. Our sample of eight jockeys and track- 
work riders was small, and some of our findings-including the results for muscular strength and power-may be a play of chance. Our sample comprised $44 \%$ of the jockey population and $24 \%$ of the track-work rider population licensed in Tasmania. Other studies involving jockeys have also reported low response proportions, ${ }^{3} 27$ and this is probably due to the demanding working lives of those in this profession. Race meetings are conducted less regularly in Tasmania than in large metropolitan areas in Australia, and thus the jockeys in this current study may be more representative of the average jockey in Australia than of elite jockeys who ride in races more often. That we had a high proportion of females among track-work riders, and a low proportion of females among jockeys, is nevertheless consistent with the population frequencies. Furthermore, only $35 \%$ of track-work riders returned their fall and injury diaries, and none of the jockeys returned theirs. It is possible that those who experienced more falls or injuries were more likely to return their diaries, leading to possible bias in the results if they also differed in respect of the factors associated with falls. Lastly, our experience has suggested that some refinements to the testing methodology are needed. To obtain better measurements of $\dot{\mathrm{VO}}_{2 \max }$, a portable gas analysis could be employed during racing and track-work. A more complex stimulus reaction time test, such as a go/no-go or choice reaction time, ${ }^{28}$ should be employed because the simple reaction time test we used was not sufficiently sensitive to differentiate between groups and individuals. Furthermore, a ridingrelevant balance test or core-stability test with higher specificity is required. Additionally, we had only selfreports of stirrup foot position. Ideally, assessment of this factor would be made by a trained, independent observer.

\section{CONCLUSION}

Riding thoroughbred racehorses is a hazardous occupation. This pilot study has confirmed that it is feasible to measure physiological attributes of jockeys and trackwork riders that are predictive of the risk of falling. We have investigated risk factors for falls among jockeys using routinely collected race-day data ${ }^{16}$ but without the insights that may be possible from actual measurements of the jockeys. What is now required is a large-scale study of the physiological attributes of jockeys that can provide the evidence base for improvements to apprentice training and remedial riding programmes designed to remedy deficits in physiological performance that lead to falls and possibly to establish minimum standards of performance for jockey licensing.

Acknowledgements The research team thank Betfair Australasia, TOTE Tasmania and the Tasmanian Thoroughbred Racing Council for funding in support of this study. Protocols to assess physiological parameters were developed in consultation with the Tasmanian Jockeys' Association. We acknowledge Racing Information Services Australia, for provision of race data, Racing Services Tasmania, for provision of stewards' reports, and T Albion, for database support.
Funding Monetary donations for this project were received from Betfair Australasia, TOTE Tasmania and the Tasmanian Thoroughbred Racing Council.

Competing interests None.

Ethical approval Ethics approval was provided by the Human Research Ethics Committee (Tasmania) (Reference Number H0009692).

Contributors All authors contributed to the analysis and interpretation of data, review and revision of the manuscript critically for important intellectual content, and provided final approval of the version to be published. Additionally, PH, LB and JF contributed to the conception and design of the study, acquisition of data and drafting of the manuscript.

Provenance and peer review Not commissioned; externally peer reviewed.

Data sharing statement Informed consent for data sharing was not obtained from participants. Additionally, data cannot be shared due to the risk of participant identification.

\section{REFERENCES}

1. Maddox D. For jockeys, small is beautiful-but difficult. Physician Sports Med 1976;4:89-94.

2. Westerling D. A study of physical demands in riding. Eur J Appl Physiol 1983;50:373-82.

3. King MB, Mezey G. Eating behaviour of male racing jockeys. Psychol Med 1987;17:249-53.

4. Apted J. Lifestyle of nine jockeys. In: Truswell AS, Wahlqvist ML, eds. Food Habits in Australia. Australia: Rene Gordon, 1988: 291-7.

5. Leydon MA, Wall C. New Zealand jockeys' dietary habits and their potential impact on health. Int $J$ Sport Nutr Exerc Metab 2002;12:220-37.

6. Warrington G, Dolan E, McGoldrick A, et al. Chronic weight control impacts on physiological function and bone health in elite jockeys. J Sports Sci 2009;27:543-50.

7. Waldron-Lynch F, Murray B, Brady J, et al. High bone turnover in Irish professional jockeys. Osteoporos Int 2010;21:521-5.

8. Trowbridge EA, Cotterill JV, Crofts CE. The physical demands of riding in National Hunt races. Eur J Appl Physiol Occup Physiol 1995;70:66-9.

9. Tobari $\mathrm{H}$, Yamagishi $\mathrm{K}$, Noda $\mathrm{H}$, et al. Body mass index and serum gamma-glutamyltransferase level as risk factors for injuries related to professional horse racing: a prospective study. J Occup Health 2009;51:323-31.

10. Gutierrez Rincon JA, Vives Turco J, Muro Martinez I, et al. A comparative study of the metabolic effort expended by horse riders during a jumping competition. Br J Sports Med 1 992;26:33-5.

11. Alfredson $\mathrm{H}$, Hedberg $\mathrm{G}$, Bergström $\mathrm{E}$, et al. High thigh muscle strength but not bone mass in young horseback-riding females. Calcif Tissue Int 1998:62:497-501.

12. Devienne MF, Guezennec CY. Energy expenditure of horse riding Eur J Appl Physiol 2000;82:499-503.

13. Lagarde J, Peham C, Licka T, et al. Coordination dynamics of the horse-rider system. J Mot Behav 2005;37:418-25.

14. Meyers MC. Effect of equitation training on health and physical fitness of college females. Eur J Appl Physiol 2006;98:177-84.

15. Hitchens PL, Blizzard CL, Jones G, et al. The incidence of raceday jockey falls in Australia, 2002-2006. Med J Aust 2009;190: 83-6.

16. Hitchens PL, Blizzard CL, Jones G, et al. Predictors of race-day jockey falls in flat racing in Australia. Occup Environ Med 2010;67:693-8

17. American College of Sports Medicine. ACSM's Guidelines for Exercise Testing and Prescription. 8th edn. Philadelphia: Lea \& Febiger/Lippincott Williams \& Wilkins, 2010.

18. Wells KF, Dillon EK. The sit and reach-A test of back and leg flexibility. Res Q Exerc Sport 1952;23:115-18.

19. Ellis L, Gastin P, Lawrens S, et al. Testing protocols for the physiological assessment of team sports players. In: Gore CJ, ed, Physiological Tests for Elite Athletes. Belconnen ACT: Australian Sport Commission, 2000:128-44.

20. Lord SR, Menz HB, Tiedemann A. A physiological profile approach to falls risk assessment and prevention. Phys Ther 2003;83:237-52.

21. Harman EA, Rosenstein MT, Frykman PN, et al. Estimation of human power output from vertical jump. J Appl Sports Sci Res 1991;5:116-20.

22. Telford RD, Minikin BR, Hahn AG. A simple method for the assessment of general fitness: the tri-level profile. J Sci Med Sport 1989;21:6-9. 
23. Craig BN, Congleton JJ, Kerk CJ, et al. Personal and nonoccupational risk factors and occupational injury/illness. Am J Ind Med 2006;49:249-60.

24. Knapik J, Ang P, Reynolds K, et al. Physical fitness, age, and injury incidence in infantry soldiers. J Occup Med 1993;35: 598-603.

25. Jones BH, Bovee MW, Harris JM III, et al. Intrinsic risk factors for exercise-related injuries among male and female army trainees. Am J Sports Med 1993;21:705-10.
26. Batti'e MC, Bigos SJ, Fisher LD, et al. Isometric lifting strength as a predictor of industrial back pain reports. Spine 1989;14: 851-6.

27. Speed $\mathrm{H}$, Seedsman $\mathrm{T}$, Morris $\mathrm{T}$, et al. The Welfare of Retired Jockeys. Victoria: Victorian University of Technology, Centre for Rehabilitation, Exercise and Sports Science, 2001.

28. Welford AT. Choice reaction time: basic concepts. In: Welford AT, ed, Reaction Times. New York: Academic Press, 1980:

$73-128$ 